\title{
Odontología legal.
}

\author{
Legal odontology.
}

\author{
Agustín Tiol Carrillo*
}

\section{RESUMEN}

El odontólogo tiene especiales obligaciones y responsabilidades que se encuentran claramente descritas en nuestra legislación. Por desgracia, es una realidad que la odontología legal es un área que comúnmente no se incluye en el plan de estudios de la licenciatura en odontología, lo que produce, como consecuencia, que los odontólogos desconozcan en gran parte sus derechos y obligaciones ante el Estado y frente a sus pacientes. El objetivo del presente artículo es indagar sobre los tópicos más relevantes de odontología legal mediante una revisión de la literatura y de conformidad con las legislaciones vigentes en la República Mexicana.

Palabras clave: Odontología legal, legislación en odontología, responsabilidad profesional.

\section{ABSTRACT}

The dentist has specific obligations and responsobilities that are clearly described in our legislation, and unfortunately it is a reality, that legal odontology is an area that is not commonly included in the curriculum of the dental degree, which results in dentists largely unaware of their rights and obligations against the State and against their patients. The aim of this article is to investigate the most relevant topics of legal odontology through a review of the literature and in accordance with the laws in force in the Mexican Republic.

Keywords: Legal odontology, dental legislation, professional responsibility.

\section{INTRODUCCIÓN}

$\mathrm{P}$ ocas veces nos detenemos a pensar que todas las actividades y situaciones de la vida cotidiana están vinculadas con el Derecho, y en realidad, desde el nacimiento hasta el fin de nuestra vida, todos los actos que realizamos tienen una trascendencia jurídica. En este mismo orden de ideas, resulta pertinente mencionar que, en muchos aspectos, la odontología tiene una enorme relación con el Derecho: desde la Ley General de Salud y las Normas Oficiales Mexicanas relacionadas con la odontología, los derechos como cirujanos dentistas, las obligaciones y derechos de los pacientes, las obligaciones que el odontólogo tiene ante el Estado y frente a cada uno de sus pacientes, y las vías legales por las cuales pueden resolverse los conflictos entre un paciente inconforme y el odontólogo tratante.
El autor del presente artículo define a la odontología legal como el estudio de la odontología, y las relaciones que ésta tiene con el Derecho, cuyo objetivo es asistir a las autoridades en la resolución de casos de orden civil, penal y administrativo.

\section{Ley General de Salud y Normas Oficiales Mexicanas}

De conformidad con el artículo 79 de la Ley Ceneral de Salud, para el ejercicio de la odontología se requiere que los Títulos profesionales o certificados de especialización sean legalmente expedidos y registrados por las autoridades educativas competentes, además, cualquier auxiliar que labore para un odontólogo requiere también diplomas que hayan sido expedidos y registrados por las autoridades educativas competentes. ${ }^{1}$ Entonces, apegán-

\footnotetext{
* Especialista en Estomatología Pediátrica, Máster en Odontología Legal y Forense. Profesor de tiempo completo en Universidad Autónoma Metropolitana-Xochimilco, CDMX.
}

Recibido: 25 Mayo 2020. Aceptado para publicación: 07 Septiembre 2020.

Citar como: Tiol CA. Odontología legal. Revista ADM 2020; 77 (5): 257-260. https://dx.doi.org/10.35366/96145

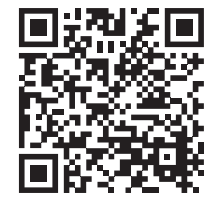


donos al marco legal, todo asistente dental debe haber tomado cursos y contar con diplomas que demuestren su conocimiento en el área.

Además, existen Normas Oficiales Mexicanas que atañen al odontólogo, como la NOM-013-SSA2-2015, que establece y uniforma los criterios y procedimientos que llevan a cabo los odontólogos para la prevención, detección, diagnóstico y tratamiento de las enfermedades bucales más frecuentes que afectan a los mexicanos, enfatizando en las acciones educativo-preventivas dirigidas a la comunidad y a la persona, medidas básicas para la prevención de riesgos, las características del expediente clínico y el registro, y notificación epidemiológica. ${ }^{2}$ También existen otras normas importantes para el odontólogo, como la NOM004-SSA3-2012, que permite profundizar en materia del expediente clínico y la NOM-087-SEMARNAT-SSA1-2002, que menciona el adecuado manejo de residuos peligrosos biológico-infecciosos en hospitales y consultorios.

\section{Responsabilidad profesional}

La labor del odontólogo representa una gran responsabilidad frente a los pacientes que tiene a su cargo. Cada vez que un paciente solicita atención a un odontólogo, se configuran derechos específicos y obligaciones por ambas partes. ${ }^{3}$ Cabe destacar que todos los derechos que un paciente tenga se convierten, sin duda, en una obligación para el odontólogo; por lo tanto, cuando existe una falta de cumplimiento de una obligación es cuando aparece el concepto de responsabilidad profesional.

Existen dos tipos de responsabilidades que pueden ser atribuidas al odontólogo cuando un paciente se muestra inconforme ante sus servicios. La primera se conoce como responsabilidad civil, y se refiere al deber que tiene una persona de responder por una conducta que haya causado un daño a otra persona; ${ }^{4}$ por tanto, este tipo de responsabilidad tiene como objetivo la reparación de daños y perjuicios sufridos directamente en la salud del paciente, siempre y cuando éstos sean producto de un tratamiento médico mal realizado. En este tipo de casos, casi siempre los pacientes buscan ser indemnizados mediante una compensación económica.

Por otra parte, cuando el odontólogo comete en su actividad profesional una acción o una omisión considerada como un delito en nuestra legislación, aparece la responsabilidad penal. Existen muchas situaciones que pueden causar este tipo de responsabilidad en contra de un odontólogo; entre las que se encuentran homicidio culposo (si bajo alguna circunstancia desafortunada el paciente pierde la vida en manos de un profesional), lesiones, abandono del paciente, revelación de secretos, suministro de medicinas nocivas o inapropiadas, daños o alteraciones a la salud y/o a la vida del agraviado, provocado por faltas de carácter administrativo, ${ }^{5}$ entre otros. Cabe resaltar que el Código Penal Federal en su artículo 228 especifica que «Cualquier profesionista, artista o técnico será responsable de los delitos producidos en el ejercicio de su profesión». ${ }^{6}$

Estos dos tipos de responsabilidades se dan por la comisión de acciones u omisiones categorizadas como negligencia, impericia, imprudencia e inobservancia ${ }^{7}$ y que, indudablemente, culminan en un daño a la salud del paciente.

Es interesante darse cuenta de que cualquiera de estas acciones cometidas por los odontólogos es totalmente prevenible, y en la mayoría de las ocasiones los mismos profesionales no son conscientes de ellas.

El odontólogo actúa con negligencia cuando, a pesar de contar con todos los conocimientos y habilidades en su área, presta atención al paciente, y por falta de ética, desidia, descuido e indiferencia, omite acciones que son necesarias para el buen pronóstico de un tratamiento, por ejemplo, no colocar dique de hule en tratamientos de conductos o de operatoria dental, no contar con un expediente clínico, ni realizar notas de evolución posteriores a un tratamiento son claros ejemplos de negligencia.

Por otro lado, cuando un odontólogo carece del conocimiento suficiente para realizar un procedimiento determinado, y como consecuencia de ello se produce una afección a la salud del paciente, entonces se configura una acción conocida como impericia, por ejemplo, realizar procedimientos de ortodoncia o cirugía bucal sin tener el total dominio de este tipo de procedimientos.

La inobservancia es una acción que se configura cuando el profesionista no presta suficiente atención al procedimiento que realiza, lo que produce inminentemente errores que resiente el paciente en su salud, por ejemplo, ejecutar accidentalmente una comunicación bucosinusal tras la extracción de un molar superior por no haber realizado un análisis radiográfico preoperatorio.

Por último, pero no menos importante, está la imprudencia, que aparece cuando el odontólogo realiza procedimientos actuando con exceso de confianza y sin prever los eventos negativos transoperatorios que podrían provocarse, por ejemplo, realizar procedimientos quirúrgicos sin conocer los antecedentes personales patológicos del paciente por haber omitido el interrogatorio en la historia clínica.

No hay que olvidar que, a pesar de que la alteración a la salud de un paciente producto de un tratamiento mal 
realizado, ya sea accidental y no intencional (es decir, culposo), el grado de responsabilidad del odontólogo no deja de existir, ya que el Artículo 9 del Código Penal Federal especifica las Reglas Generales sobre los Delitos y Responsabilidad, además, menciona que «obra culposamente quien produzca un daño sin intención a un tercero que no previó siendo previsible o confiando en que no se produciría», ${ }^{6}$ y en este mismo tenor, el Artículo 1910 del Código Civil Federal especifica que «El que obrando ilícitamente o contra las buenas costumbres cause un daño a otro, está obligado a repararlo». ${ }^{8}$ Por lo que la responsabilidad profesional médica no se consume ni desaparece, a pesar de que el daño ocasionado haya sido accidental.

Por último, cabe destacar que los pacientes cuya salud haya sido afectada por un profesional, podrán externar su inconformidad ante la CONAMED, o por vía judicial civil o penal, según sea la naturaleza jurídica del hecho que se desea denunciar, pues el ser atendidos cuando exista inconformidad por la atención médica recibida es un derecho que todo paciente tiene, el cual está especificado en el artículo 77 Bis 37 de la Ley General de Salud. ${ }^{1,9}$

\section{Apertura de consultorios odontológicos}

La apertura de un consultorio en nuestro país exige un conjunto de requisitos que deben cumplirse para evitar problemas legales y administrativos.

La obtención del Registro Federal de Contribuyentes, el trámite de la Firma Electrónica (e-firma) y el registro de actividad económica ante el Servicio de Atención Tributaria (SAT) es de vital importancia como primer paso para la apertura de un consultorio.

Asimismo, y de conformidad con la Ley General de Salud en Materia de Prestación de Servicios de Atención Médica, debe tramitarse en la oficina de regulación sanitaria el Aviso de funcionamiento y el Aviso de responsable sanitario; ${ }^{10}$ además de la emisión de una cédula de cumplimiento ante las oficinas de la Dirección General de Protección Civil. Por último, no debe omitirse dar aviso al gobierno local para la emisión de la licencia de uso de suelo y de anuncio denominativo. ${ }^{11}$

\section{Regulación sanitaria}

Una de las obligaciones de la Secretaría de Salud es la regulación, control y fomento sanitario, y delega esta responsabilidad a la Comisión Federal para la Protección contra Riesgos Sanitarios (COFEPRIS). ${ }^{12}$

La COFEPRIS, por tanto, es la encargada de realizar visitas de verificación y fomento sanitario a consultorios médicos y dentales, únicamente para supervisar que se han cumplido las especificaciones establecidas en nuestra legislación, y, de no hacerlo, la COFEPRIS tiene la obligación de sancionar a aquellos profesionales que presten servicios a pacientes sin apegarse a nuestras leyes y normatividades, estas sanciones son múltiples y están claramente descritas en la Ley General de Salud del Artículo 416 al 437 y pueden ser: clausura o suspensión total o parcial del consultorio, multa económica o arresto. ${ }^{1}$

Cabe resaltar que, para evitar sanciones por parte de la autoridad sanitaria, el odontólogo debe apegarse a la legislación sanitaria vigente en México, y estructurar el consultorio de conformidad con la NOM-005-SSA3-2016, que establece los requisitos mínimos de infraestructura y equipamiento de establecimientos de atención médica de pacientes ambulatorios, ${ }^{13}$ y a su vez, se debe cumplir con otros requisitos obligatorios como contar con expedientes clínicos, tener el título del odontólogo a la vista del público, botiquín de primeros auxilios, un rótulo que indique horarios de atención, tener un contrato con una empresa recolectora de residuos peligrosos biológicoinfecciosos (RPBI) y de fumigación, contar con baños funcionales, adecuaciones para el ingreso de personas con discapacidad, entre otros. ${ }^{12}$

\section{Obligaciones fiscales}

Nuestra Constitución especifica con claridad que todos los mexicanos tienen la obligación de contribuir al gasto público, por medio del pago de impuestos proporcionales y equitativos a los ingresos de cada individuo. ${ }^{14}$

Todos aquéllos que perciban ingresos derivados de la prestación de servicios profesionales están obligados al pago del Impuesto Sobre la Renta (ISR), según lo especifica el artículo 100 la Ley del Impuesto sobre la Renta. ${ }^{15}$

Como ya se mencionó con anterioridad, los odontólogos tienen la obligación legal de darse de alta ante el SAT pues, por su actividad profesional, perciben ingresos y paga salarios a sus trabajadores, a quienes se les debe retener el ISR de su salario. Asimismo, no es raro que los pacientes que solicitan atención dental a nivel particular pidan al odontólogo tratante la expedición de un recibo de honorarios.

Por todo lo anterior, el dentista está obligado a emitir las declaraciones mensuales y anuales del ISR.

Es verdaderamente importante que los profesionales de la salud presenten mes con mes sus declaraciones, pues la evasión fiscal puede traer graves consecuencias legales a quien incurra en este tipo de omisiones. 


\section{CONCLUSIÓN}

Como se pudo observar a lo largo del presente artículo, todo profesional de la salud tiene específicas obligaciones que establecen nuestras normas y leyes, por lo que es muy importante que todo estomatólogo se mantenga correctamente informado y actualizado sobre la legislación vigente en México, tomando en cuenta que las leyes y normas son dinámicas y pueden ser modificadas cada año.

Apegarse a la ley en nuestra actividad profesional es, sin duda, la mejor recomendación que se puede hacer al odontólogo para evitar problemas legales en el ámbito civil, penal y administrativo.

\section{BIBLIOGRAFÍA}

1. Ley General de Salud. 2019.

2. Norma Oficial Mexicana NOM-0013-SSA2-2015. Para la prevención y control de enfermedades bucales. Diario Oficial de la Federación.

3. Carta de los Derechos Generales de los Pacientes. Comisión Nacional de Arbitraje Médico.

4. Villegas ZA. Responsabilidad civil profesional del médico. Revista Médica de Costa Rica y Centroamérica 2013; 70 (607): 389-393.
5. García Gl. Procedimiento pericial médico-forense. Normas que lo rigen y los derechos humanos. México: Porrúa; 2012, pp. 77-78.

6. Código Penal Federal. 2020.

7. Tiol-Carrillo A. El peritaje odontológico forense. Rev Odont Mex. 2016; 20 (3): 154-156.

8. Código Civil Federal. 2018.

9. Valle GA, Fernández Varela MH. Arbitraje, médico. Fundamentos teóricos y análisis de casos representativos. México: Trillas, 2014, pp. 48-49.

10. Reglamento de la Ley General de Salud en Materia de Prestación de Servicios de Atención Médica. Diario Oficial de la Federación. 2016.

11. Ramírez-Fernández DM. Requisitos para la apertura de un consultorio odontológico en México. Revista ADM. 2019; 76 (1): 38-43.

12. Tiol-Carrillo A. COFEPRIS: las auditorías de establecimientos de atención odontológica. Rev Mex Ortodon. 2017; 5 (4): 202-204.

13. Norma Oficial Mexicana NOM-005-SSA3-2016, que establece los requisitos mínimos de infraestructura y equipamiento de establecimientos de atención médica de pacientes ambulatorios. Diario Oficial de la Federación.

14. Constitución Política de los Estados Unidos Mexicanos. 2020.

15. Ley del Impuesto sobre la Renta. 2019.

\author{
Correspondencia: \\ Agustín Tiol Carrillo \\ E-mail: agustintiolcarrillo@gmail.com
}

